\title{
Non-binary or genderqueer genders
}

\section{Christina Richards, Walter Pierre Bouman, Leighton Seal, Meg John Barker, Timo O. Nieder \& Guy T'Sjoen}

To cite this article: Christina Richards, Walter Pierre Bouman, Leighton Seal, Meg John Barker, Timo O. Nieder \& Guy T'Sjoen (2016) Non-binary or genderqueer genders, International Review of Psychiatry, 28:1, 95-102, DOI: 10.3109/09540261.2015.1106446

To link to this article: http://dx.doi.org/10.3109/09540261.2015.1106446

\section{曲 Published online: 12 Jan 2016.}

\section{Submit your article to this journal ¿}

Џll Article views: 1658

Q View related articles $\sqsubset$

View Crossmark data ¿

Citing articles: 1 View citing articles 


\title{
Non-binary or genderqueer genders
}

\author{
Christina Richards ${ }^{\mathrm{a}, \mathrm{b}}$, Walter Pierre Bouman ${ }^{\mathrm{a}}$, Leighton Seal ${ }^{\mathrm{b}}$, Meg John Barker ${ }^{\mathrm{c}}$, Timo O. Nieder ${ }^{\mathrm{d}}$ \\ and Guy T'Sjoen ${ }^{\mathrm{e}}$ \\ ${ }^{a}$ Nottingham Centre for Gender Dysphoria, Nottingham, UK; ${ }^{b}$ Charing Cross Gender Identity Clinic, London, UK; ${ }^{c}$ Department of \\ Psychology in Social Sciences, Open University, Milton Keynes, UK; ${ }^{d}$ Interdisciplinary Transgender Health Care Centre Hamburg, \\ Department for Sex Research and Forensic Psychiatry, University Medical Centre Hamburg-Eppendorf (UKE), Germany; ${ }^{\mathrm{e} C e n t r e}$ for \\ Sexology and Gender, Department of Endocrinology, Ghent University, Belgium
}

ABSTRACT

Some people have a gender which is neither male nor female and may identify as both male and female at one time, as different genders at different times, as no gender at all, or dispute the very idea of only two genders. The umbrella terms for such genders are 'genderqueer' or 'non-binary' genders. Such gender identities outside of the binary of female and male are increasingly being recognized in legal, medical and psychological systems and diagnostic classifications in line with the emerging presence and advocacy of these groups of people. Population-based studies show a small percentage - but a sizable proportion in terms of raw numbers - of people who identify as non-binary. While such genders have been extant historically and globally, they remain marginalized, and as such - while not being disorders or pathological in themselves - people with such genders remain at risk of victimization and of minority or marginalization stress as a result of discrimination. This paper therefore reviews the limited literature on this field and considers ways in which (mental) health professionals may assist the people with genderqueer and non-binary gender identities and/or expressions they may see in their practice. Treatment options and associated risks are discussed.
ARTICLE HISTORY

Received 29 June 2015

Accepted 6 October 2015

Published online 8 January

2016

\section{KEYWORDS}

Gender; Genderqueer; Non-binary; Transgender; Transsexual

\section{Introduction}

Gender is often considered to come in two forms - male (masculine) or female (feminine). Indeed, it is frequently elided with physical sex such that when a person is assigned a female sex at birth - through visual inspection of their external genitals - it is assumed that their gender too will be female; that they will likely be feminine (their gender role); and that they will most likely be sexually attracted to men when they reach sexual maturity. Of course, this series of inferences is correspondingly made with men - linking sex to gender, to gender role, to sexuality. It is a trivial assertion, however, to say that these inferences are not invariably correct. For example, male people may be attracted to other male people; people assigned male at birth may have a female gender identity; and people assigned female may have a male gender identity but, for pragmatic reasons, have a female gender role (Richards \& Barker, 2013, 2015).

All these acknowledged variations nonetheless still presuppose a binary system of male and female, albeit that 'male' and 'female' here may be expressed in different ways, e.g. as gender, sex, gender role. Notwithstanding this, people with an intersex or diversity/disorder of sexual development (DSD) condition (APA, 2013a) will have physical sexual characteristics which fall outside of this binary (Roen, 2015); although the majority of people with this range of conditions do still identify their gender within the binary as men or as women (Harper, 2007; Richards \& Barker, 2013).

In contrast to this, there are a significant number of people who do not have an (observable) intersex/DSD condition, but who nonetheless identify outside of the gender binary. Such non-binary gender identity or expression has been present over time and across different global cultures (Herdt, 1996).

In the current Western context, however, some people may identify as predominantly male, but with aspects of the 'other' gender and use the identity term 'male' generally; or may identify as predominantly female, but with aspects of the 'other' gender and use the identity term 'female' generally - but both groups of people may define additionally as 'genderqueer' when necessary - for example in accepting environments or when neither a male nor female identity suits. Those people who incorporate aspects of both male and female, but who 
have a fixed identity, may identify as 'androgynous', 'mixed gender' or sometimes 'pangender' as the latter is a flexible term. In contrast, people who move between genders in a fluid way may identify as 'bigender', 'gender fluid' or sometimes 'pangender' again. Some people move between more than two genders and so identify as 'trigender', and sometimes 'pangender' as it is a flexible term. Some people identify as a specific additional gender (either between female and male or otherwise additional to those genders) and identify as 'third gender', 'other gender', and sometimes again as 'pangender'. Then there are those people who disrupt the gender dichotomy though challenging its very ontology and/or veracity and so identify as 'genderqueer' or 'genderfuck'. And there are also people who have no gender and so identify as 'agender', 'gender neutral', 'non-gendered', 'genderless', 'neuter', or 'neutrois'.

An example of this is present in Bockting (2008) who found in the course of a US online study a variety of identities amongst 1229 transgender individuals that were not reconcilable with a binary understanding of sex. These included 'shemale, bigender, two-spirit, gender neutral, genderless, androgyne, ambiguous, intergendered, third gender, pan-, poly- or omni-gendered, dynamically gendered, gender fluid, nonbiological intersexed, in-between and beyond' (Bockting, 2008, p. 214). In her qualitative study, Hines (2007) quotes such further non-binary identities as 'gender terrorist, intersex by design, intentional mutation, hermaphrodyke, queer trannie boy' (Hines, 2007, p. 80). All of the above terms are often subsumed within the umbrella terms of 'nonbinary' or 'genderqueer' identities. In this emerging field terms are likely to change, however, and, as usual, we should attend to people's own preferred terms when undertaking clinical work. Moreover, it is important to use people's preferred pronouns (in addition to names and terms for gender). Some non-binary people use they/ their/them/themselves or an explicitly developed term such as $\mathrm{xe} / \mathrm{xyr} / \mathrm{xem} / \mathrm{xyrself}$ rather than he/his/him/himself or she/her/her/herself. With all these aspects, 'ask' etiquette is appropriate (Richards \& Barker, 2013) which simply involves asking what terminology people prefer and how they experience their gender. This move towards a more accepting and accommodating approach towards non-binary and genderqueer people is mirrored in generally more favourable media reporting within the global North and West, especially in online and youth oriented media. Within mainstream media there is still a tendency towards a perhaps patronizing 'interest' which situates non-binary and genderqueer people as 'other' to the assumed norm of the viewer - something which can be tiring for these minority groups (Sue, 2010).
This paper then, consists of a necessarily extremely brief overview of the current psychiatric literature pertaining to such non-binary or genderqueer identities as these have formed the basis of the literature until now. It then considers how (mental) health professionals might assist these groups of people within clinical practice in a non-pathologizing manner, which recognizes the pressures and needs of this group of people at this time in history.

\section{Prevalence of non-binary people}

Two population studies have aimed to estimate the prevalence of people who identify as non-binary. Kuyper \& Wijsen (2014) examined self-reported gender identity and dysphoria in a large Dutch population sample ( $\mathrm{N}=8064$, aged $15-70$ years old), and found that $4.6 \%$ of people assigned male at birth and $3.2 \%$ of people assigned female at birth reported an 'ambivalent gender identity' (defined as equal identification with the other sex as with the sex assigned to them at birth) and $1.1 \%$ of people assigned male at birth and $0.8 \%$ of people assigned female at birth reported an 'incongruent gender identity' (defined as stronger identification with the other sex as with the sex assigned to them at birth). Recently, Van Caenegem et al. (2015) reported results based on two population-based surveys, one of 1832 Flemish individuals and one of 2472 sexual minority individuals in Flanders, Belgium, examining the prevalence of 'gender incongruence' (defined as identifying stronger with the other sex than with the sex assigned at birth) and 'gender ambivalence' (defined as identifying equally with the other sex as with the sex assigned at birth). Their findings showed that the prevalence of 'gender ambivalence' or non-binary gender was $1.8 \%$ in natal men and $4.1 \%$ in natal women.

In terms of trans populations more specifically, one UK study found that 5\% of Lesbian, Gay, Bisexual, Trans and Questioning (LGBTQ) youth identified as neither male nor female (METRO Youth Chances, 2014); a US study found that $13 \%$ of trans people surveyed were 'a gender not listed here' (Harrison et al., 2012, p. 14); and a Scottish study on trans mental health (McNeil et al., 2012) found that over a quarter of survey participants identified as non-binary.

Turning to wider gender experience and expression, rather than specific identities, it seems that the figures are likely to be much higher. Joel et al. (2013) surveyed people in the general population in Israel and found that, out of 2225 participants, over $35 \%$ felt that they were to some extent the 'other' gender, 'both' genders, and/or neither gender. 
These are clearly significant proportions of people; however, comparatively few appear to seek any form of assistance at gender identity clinics. For example, in Beek et al. (unpublished), out of 360 applicants for gender reassignment treatments only four explicitly stated that their non-binary identity was their motivation for treatment. This may, of course, be related to the number of non-binary people who feel able to be open about their identities in such settings.

\section{Human rights and legislation for non-binary people}

Many of the non-binary groups of people listed above will use their birth-assigned gender as a matter of necessity in day-to-day business and bureaucracy due to the fact that many systems (including health systems) and social circles only recognize binary genders. This is changing, however. For example the European Union's Council of Europe Parliamentary Assembly Resolution 2048 6.2.4 recommends that European Parliaments 'Consider including a third gender option in identity documents for those who seek it' (Council of Europe, 2015). Similarly, the United Nations' (UN) General Assembly Report of the United Nations High Commissioner for Human Rights Discriminatory laws and practices and acts of violence against individuals based on their sexual orientation and gender identity (United Nations, 2015) advocates for fair treatment of LGBT people in all UN member states and notes that:

The terms lesbian, gay and bisexual and transgender are used throughout the report, but often abbreviated to LGBT. These terms are used to refer to same-sex behaviour, identities or relationships and non-binary gender identities. (United Nations, 2015, p. 4; italics not in the original.)

Thus the report includes non-binary people within its purview and consequently within international law. Notably, holders of New Zealand passports may already have their gender marked as male $(\mathrm{M})$, female $(\mathrm{F})$, or as neither male nor female (X). More broadly, organizations from Facebook to the United Kingdom's Royal Mail are including non-binary genders as gender options for their customers. It follows, therefore, that health professionals should attend to this cultural shift in their work.

\section{Diagnostic classification concerning non-binary people}

This trend toward acceptance, as well as a greater understanding of the diversity of gender, has been reflected within the context of mental health care as in the last revision to the American Psychiatric Association's (APA, 2013a) Diagnostic and statistical manual fifth edition (DSM-5). The DSM-5 removed the DSM IV-TR (APA, 2000) diagnosis of gender identity disorder which considered wishing to change one's gender to be a disorder and only recognized the gender binary of male and female. The DSM-5 instead includes the diagnosis of gender dysphoria which explicitly recognizes that having a different gender is not a disorder (APA, 2013b) and crucially includes the criteria:

- 4. A strong desire to be of the other gender (or some alternative gender different from one's assigned gender)

- 5. A strong desire to be treated as the other gender (or some alternative gender different from one's assigned gender)

- 6. A strong conviction that one has the typical feelings and reactions of the other gender (or some alternative gender different from one's assigned gender). (APA, 2013a p. 452; italics not in the original.)

Thus non-binary genders are recognized with the APA's diagnostic taxonomy also. There are, of course, strong arguments for removing diagnoses pertaining to gender from the DSM entirely as there are no higher rates of psychopathology in this demographic (Cole et al., 1997; Colizzi et al., 2014; Haraldsen \& Dahl, 2000; Hill et al., 2005; Hoshiai et al., 2010; Kersting et al., 2003; Simon et al., 2011). Of course this does not include wider psychological distress, most commonly minority or marginalization stress, which is stress caused by being in a group which is discriminated against and so may lead to psychopathology - it is the discrimination rather than the membership of this specific group which is psychopathogenic.

Nonetheless, gender diagnoses have been retained predominantly for the purely pragmatic reason that some people who do not remain in the gender they were assigned at birth wish for interventions such that they have a more holistically congruent self. This might include such things as hormones, chest surgeries, and genital surgeries of various sorts to give people a body more in keeping with their gender; or psychological and counselling assistance to assist with psychosocial transitions (Richards et al., unpublished). Consequently the World Health Organization's (WHO) forthcoming revision of the International classification of diseases and related health problems (ICD-11), which is expected to be published in 2017 will likely remove the diagnostic category 'gender identity disorders' from chapter V (Mental and behavioural disorders) of the ICD-10 (WHO, 1992) (which again used a disorder and binary gender model). The recommendation from the Working Group on the Classification of Sexual Disorders and Sexual Health is to replace it with a diagnosis of 'gender 
Table 1. Number of PubMed results by term.

\begin{tabular}{llll}
\hline & \multicolumn{3}{c}{ Qualifying search term } \\
\cline { 2 - 4 } Search term & (None) & Non-binary & Genderqueer \\
\hline Genderqueer & 5 & 0 & $\mathrm{n} / \mathrm{a}$ \\
Non-binary & 54 & $\mathrm{n} / \mathrm{a}$ & $\mathrm{n} / \mathrm{a}$ \\
Trans & 264,531 & 4 & 1 (Moody \& \\
& & \multicolumn{3}{c}{ Smith, 2013) } \\
Transsexual & 976 & 0 & 1(Moody \& \\
& & \multicolumn{2}{c}{ Smith, 2013) } \\
Disorder of sexual development \\
$\begin{array}{llll}\text { Diversity of sexual development } \\
\text { Intersex }\end{array}$ & 705,871 & 0 & 0 \\
\hline
\end{tabular}

n/a, not applicable.

incongruence', which does not include the assumption of disorder and again includes non-binary or genderqueer identities. They further asserted that based on more reflective and contemporary scientific evidence and best practice there is merit in placing gender incongruence in an entirely separate ICD chapter that would contain no other entities (Drescher et al., 2012).

\section{Prevalence of studies in the literature}

A PubMed search was carried out on 10 April 2015 in an endeavour to undertake an examination of the extant peer-reviewed medical literature (see Table 1). Some items returned multiple false positive entries (i.e. trans because it is a homonym) in which case only the first 100 entries were reviewed and articles were excluded as necessary.

As peer reviewed literature on genderqueer and nonbinary identities is evidently extremely rare, that which was found was snowballed to further include literature which electronic engines have not adequately catalogued. Further, the authors' own very recent work was included, as well as the legal and prevalence items mentioned above. Lastly, some consideration was given to the grey and community literatures as these are a rich source of information on this emerging field, which will not be listed on PubMed. Given the heterogeneity of this literature, both in source and type, it has been included in a bricolage above and below, rather than in a positivist fashion.

\section{A discussion of the literature}

Non-binary people might appear to be a relatively recent and under-researched phenomenon, but it is likely that some people who previously would have identified as trans(sexual) - that is within the gender binary, but moving across it - may have identified outside of the binary if that discourse had been available to them. However, it is very likely that they were not distinguished as such but were instead diagnosed as having a gender identity disorder not otherwise specified by gender teams at medical centres; and have only become increasingly visible in recent years (Hage \& Karim, 2000, Nieder \& Richter-Appelt, 2011). An analogy may be drawn with the number of lesbian and gay people who became able to identify their sexualities within contemporary Western societies when the possibility to do so became more available and the identities became more widely understood and accepted. This also applies, to a lesser extent, to bisexual people, as bisexuality remains relatively invisible (Barker et al., 2012). Further, some nonbinary and genderqueer people may have been reticent to foreground their identities for fear that they would not receive the physical testaments they desired. Hopefully, compassionate clinical practice is now assisting this group of people to feel comfortable presenting to get their true needs met.

People who are now re-self-defining to a non-binary identity are also increasingly availing themselves of the possibilities afforded by the change in legal and bureaucratic systems - for example by using the title ' $\mathrm{Mx}$ ' and making a change of name to reflect their gender more accurately (a non-gendered name, initials only, or including both masculine and feminine names, for example). Other strategies enabling genderqueer people to express their non-binary identifications appropriately in a day-to-day context include the following (for detailed information see Nieder, 2014):

- Stretching: Making the established identity categories of femininities or masculinities more flexible (Connell, 2005),

- Diversifying gender: Based on the concept of a continuum whose graduations manifest themselves via the interaction of sex characteristics, subjective gender experiences, and expressions (Monro, 2007),

- Dissolution or negation of sex difference: Pursued by the genderqueer movement in particular (Bornstein \& Bergman, 2010; Nestle et al., 2002) with the goal of a 'non-gendered social order' (Monro, 2010, p. 246),

- Creating ambiguity: To express gender in a way that defies a mono-sex assignment that is exclusive and fixed over the life course (Engel, 2002).

It is therefore beholden on (mental) health care providers to respect these different strategies and to integrate them into their work.

When working with people who are existing psychiatric patients, professionals may understandably be concerned that an 'atypical' gender is as a result of some psychopathology such as psychosis or emotionally unstable personality disorder. However, as with the pathologization of homosexuality in the past, it is vital not to pathologize a non-pathological identity, or to see 
it as pathology when it is 'co-morbid', in a way that we would not with a binary gender (or heterosexuality).

Certainly there is no evidence to suggest that nonbinary genders are pathological. Indeed what evidence there is suggests quite the reverse. It is worth considering that there are no psychological fields in which male and female are discrete (Fine, 2010) and that the overlap is always greater than any difference (Maccoby \& Jacklin, 1974). This is clearly adaptive as it enables both men and women to carry out the variety of tasks required of them, and consequently those people who are more 'sex typed' - that is further towards the ends of a notional gender spectrum - are disabled by their rigid adherence to their gender role (Bem \& Lenney, 1976). Indeed, exposure to gender role stereotypes diminishes confidence and interest in 'the other gender's fields' such as mathematics for women (Correll, 2004), as well as actual performance in them (McGlone \& Aronson, 2006).

(Mental) health professionals, then, may best serve their patients by supporting them in their identities and expressions and affirmatively exploring identities if that is the presenting problem. Empirical research in this area would also be most welcome. In addition, psychiatrists, psychologists and other clinicians may usefully utilize their clinical skills as necessary to assist with psychosocial transitions associated with non-binary genders. This will include such things as addressing anxiety around coming out to others and being seen in public, consideration of intimate relationships and family, sexuality and reproductive options, and consideration of physical interventions aimed at the bodily and psychological comfort of the non-binary person.

Those non-binary people who are seeking approval for physical interventions should be compassionately assisted, perhaps referring to standards of care such as the World Professional Association for Transgender Health's (WPATH, 2011) Standards of care for the heath of transsexual, transgender and gender nonconforming people or the Royal College of Psychiatrists' CR181, Good practice guidelines for the assessment and treatment of gender dysphoria (Wylie et al., 2014).

It is important to note here the differences and similarities between trans people who make physical gender changes within the binary, and non-binary people who do not, as this is important in planning appropriate support for individuals. A significant number of trans people decide not to undergo surgical interventions to address the incongruence between their physical and mental gender (Bockting, 2008; WPATH, 2011). This does not, in and of itself, define the individual as having a non-binary gender identity, and the support and health care needs of these individuals will differ from those with a non-binary gender identity.
When considering physical interventions then, the means for achieving overt masculinization or feminization is quite established (Gooren, 2011) but in order to guide genderqueer individuals in hormonal and/or surgical treatments, and to predict their effect short or long term, we have to creatively rely on principles of treatment in trans men or women, or - in the case of hormones - on data and treatment from related endocrine conditions such as hypogonadism, precocious puberty, polycystic ovarian syndrome, menopausal replacement therapy, infertility, DSD, and on principles of hormonal contraceptives.

Indeed, when relying on such information we much also note that the physical intervention needs of nonbinary individuals are diverse. For example, as with trans people within the gender binary, some do not desire any such interventions. However, for a significant minority it is most important to remove obvious markers of masculinity or femininity (e.g. breasts or facial/body hair). Others wish to combine such markers, or may be taking a more conventional trans masculine or feminine treatment path whilst maintaining a non-binary identity. For example, Rankin \& Beemyn (2012) found that some non-binary people who were assigned female at birth had chest surgery and/or took hormones. Others did not engage in these methods, but modified some visible markers of gender in other ways, including breast binding, having a traditionally male hairstyle, not shaving their body hair, bodybuilding, and/or packing their groin region to give a stereotypically male contour. Non-binary people who were assigned male at birth similarly had varying relationships to hormones/surgeries. They frequently did things such as wearing makeup, having long hair, removing body/facial hair, and/or wearing 'feminine' jewellery. Some people liked to destabilize conventional markers of gender by dressing androgynously, by combining 'men's' and 'women's' clothing, and/or by dressing in clothing associated with a different gender. Some made similar shifts in mannerisms such as gait, making eye contact, and sitting with legs together or apart.

It is clear that the endocrine possibilities or limitations for this specific group are, so far, not described in the medical literature and indeed it is likely that a proportion of this group are self-medicating with the attendant risks (Rotondi et al., 2013). Further, cosmetic interventions may be sufficient to achieve partial feminization. Breast implants can be considered safe, as is laser epilation, even if the effect on skin is thought to be less successful in the absence of hormonal treatment. The role of the hormone-prescribing physician is therefore to liaise with the multidisciplinary team as necessary and to monitor the effects and mostly cardiovascular side effects of 
anti-androgens/oestrogens or testosterone treatment, and to try to modify cardiac risk factors through advising diet, exercise, and smoking cessation, and to encourage routine surveillance of glycaemia, lipids, haematocrit and bone mineral density. A second important role is in counselling the individual about what hormonal therapy is able to achieve, so that the individual's expectations of therapy can be aligned with what is possible with current hormonal treatments, and the impact of treatment on physical health discussed.

Given the lack of literature on this topic, referral to an endocrinologist may be useful. For people assigned male at birth, the endocrinologist can decide with the client on anti-androgen or oestrogen monotherapy, with variable dosage or intermittent use. Unfortunately, no data on small dosage anti-androgen therapy is available. Gonadotropin releasing hormone agonists or antagonists may be less desired for this group since absolute testosterone suppression would be achieved; however, used in combination with androgen and oestrogen they could offer the possibility of tailoring the hormonal milieu of the individual without surgical interventions such as gonadectomy. Lower dosage oral anti-androgen treatment (finasteride, cyproterone acetate or spironolactone) can create moderate androgen deprivation, possibly leading to interruption of the process of androgenetic alopecia, somewhat less virilization, and the development of the desired mild gynaecomastia. Erectile dysfunction that may occur can be treated with PDE-V inhibitors on demand. All hormonal interventions should, of course, be preceded by a discussion on the effect on fertility (Richards \& Seal, 2014; T'Sjoen et al., 2013) although it is worth noting that interruption of hormonal treatment is likely to restore spermatogenesis over a period of 6 months. The occurrence of metabolic side effects of high-dose anti-androgen therapy, such as used in prostate cancer or sex offenders, can be considered modest. If feminizing hormone therapy is used long term, without the desire for genital surgery, probably no specific oncological concerns are needed for the testicular tissue, and breast cancer is rarely reported (Gooren et al., 2013). Indeed, prostate cancer is rarely reported in trans women, but it does occur and continuous monitoring has to be considered in all those undergoing anti-androgen therapy (Gooren \& Morgentaler, 2014).

For people assigned female at birth, partial virilization can be achieved through different therapies, depending on the wish of the client. Interruption of menstrual bleeding can be achieved by use of continuous progestins or intrauterine devices. Prolonged intake of combined oral contraceptive pills will lead to amenorrhoea, but clients have to be warned about the possibly of spotting or irregular and unpredictable menses as there will be a $30 \%$ increased oestrogen intake. Use of dihydrotestosterone is often desired, but remains barely described; as is low dose or intermitted treatment with testosterone. It has to be considered that exogenous testosterone is aromatized to oestrogen, and if no surgical steps are taken, monitoring for breast, cervix, endometrium or ovarian cancer remain necessary. Hormone-dependent cancers have been rarely reported in trans men and so may also be the case here. Fertility seems preserved, as has been shown in popular literature, and virilization does not disappear if testosterone is temporarily interrupted for this cause, but specific guidance remains undescribed.

\section{Conclusion}

Recent reports indicate that the overall number of individuals with gender dysphoria who attend clinical services for an assessment has increased substantially over the years in many North American and European countries (Aitken et al, 2015; De Vries et al, 2015). There is also a significant increase in people who self-diagnose as suffering from gender dysphoria and gender incongruence (Kuyper \& Wijsen, 2014; Van Caenegem et al., 2015).

Although the proportion of people who identify as non-binary and seek gender-related treatment within the aforementioned research remains unknown, it is highly likely that an increasing amount of non-binary people will present to clinical services seeking treatment. In the absence of clinical guidelines and treatment protocols for this group, prospective outcome studies are vital and timely. In the mean time we urge careful compassionate assistance for this patient group.

\section{Declaration of interest}

The authors report no conflicts of interest. The authors alone are responsible for the content and writing of the paper.

\section{References}

Aitken, M., Steensma, T.D., Blanchard, R., VanderLaan, D.P., Wood, H., Fuentes, A., ... Zucker, K.J. (2015). Evidence for an altered sex ratio in clinic-referred adolescents with gender dysphoria. Journal of Sexual Medicine, 12, 756-763.

American Psychiatric Association (APA). (2000). Diagnostic and statistical manual of mental disorders 4-TR. Washington, DC: American Psychiatric Association.

APA (American Psychiatric Association). (2013a). Diagnostic and statistical manual of mental disorders, 5th edition (DSM-5). Washington, DC: American Psychiatric Association. 
APA (American Psychiatric Association). (2013b). Gender dysphoria fact sheet. Retrieved from http://www.dsm5.org/ Documents/Gender\%20Dysphoria\%20Fact\%20Sheet.pdf

Barker, M., Richards, C., Jones, R., Bowes-Catton, H., \& Plowman, T. (2012). The bisexuality report. Milton Keynes: Open University, Centre for Citizenship, Identity and Governance.

Bem, S.L., \& Lenney, E. (1976). Sex typing and the avoidance of cross-sex behavior. Journal of Personality and Social Psychology, 33, 48-54.

Bockting, W.O. (2008). Psychotherapy and the real-life experience: From gender dichotomy to gender diversity. Sexologies, 17, 211-224.

Bornstein, K., \& Bergman, S.B. (Eds). (2010). Gender outlaws: The next generation. Berkeley, CA: Seal Press.

Cole, C.M., O’Boyle, M., Emory, L.E., \& Meyer, W.J. (1997). Comorbidity of gender dysphoria and other major psychiatric diagnoses. Archives of Sexual Behavior, 26, 13-26.

Colizzi, M., Costa, R., \& Todarello, O. (2014). Transsexual patients' psychiatric comorbidity and positive effect of crosssex hormonal treatment on mental health: Results from a longitudinal study. Psychoneuroendocrinology, 39, 65-73.

Connell, R. (2005). Masculinities. Cambridge: Polity Press.

Correll, S.J. (2004). Constraints into preferences: Gender, status, and emerging career aspirations. American Sociological Review, 69, 93-113.

Council of Europe. (2015). Discrimination against transgender people in Europe, Resolution 2048. Strasbourg: Council of Europe Parliamentary Assembly.

de Vries, A.L.C., Kreukels, B.P.C., T’Sjoen, G., Ålgars, M., \& Mattila, A. (2015). Increase of referrals to gender identity clinics: A European trend? EPATH (Ed) In Transgender healthcare in Europe. Book of abstracts (p. 10). Ghent, Belgium: European Professional Association of Transgender Health (EPATH). 2015. Retrieved from http://epath.eu/wpcontent/uploads/2014/07/EPATH-2015-Book-ofAbstracts.pdf

Drescher, J., Cohen-Kettenis, P., \& Winter, S. (2012). Minding the body: Situating gender identity diagnoses in the ICD-11. International Review of Psychiatry, 24, 568-577.

Engel, A. (2002). Wider die Eindeutigkeit. Sexualität und Geschlecht im Fokus queerer Politik der Repräsentation. [Against unambiguousness: Sex and gender in the focus of queer representation politics]. Frankfurt: Campus.

Fine, C. (2010). Delusions of gender: How our minds, society, and neurosexism create difference. New York: Norton.

Gooren, L. (2011). Care of transsexual persons. New England Journal of Medicine, 364, 1251-1257.

Gooren, L., \& Morgentaler, A. (2014). Prostate cancer incidence in orchidectomised male-to-female transsexual persons treated with oestrogens. Andrologia, 46, 1156-1160.

Gooren, L.J., van Trotsenburg, M.A., Giltay, E.J., \& van Diest, P.J. (2013). Breast cancer development in transsexual subjects receiving cross-sex hormone treatment. Journal of Sexual Medicine, 10, 3129-3134.

Hage, J.J., \& Karim, R.B. (2000). Ought GIDNOS get nought? Treatment options for nontranssexual gender dysphoria. Plastic and Reconstructive Surgery, 105, 1222-1227.

Haraldsen, I.R., \& Dahl, A.A. (2000). Symptom profiles of gender dysphoric patients of transsexual type compared to patients with personality disorders and healthy adults. Acta Psychiatrica Scandinavica, 102, 276-281.

Harper, C. (2007). Intersex. Oxford: Berg.

Harrison, J., Grant, J., \& Herman, J.L. (2012). A gender not listed here: Genderqueers, gender rebels, and otherwise in the National Transgender Discrimination Survey. Los Angeles, CA: eScholarship, University of California.

Herdt, G. (1996). Third sex third gender. New York: Zone.

Hines, S. (2007). TransForming gender: Transgender practices of identity, intimacy and care. Bristol: Policy Press.

Hill, D.B., Rozanski, C., Carfagnini, J., \& Willoughby, B. (2005). Gender identity disorders in childhood and adolescence: A critical inquiry. In D. Karasic \& J. Drescher (Eds), Sexual and gender diagnoses of the diagnostic and statistical manual (DSM). New York: Haworth Press.

Hoshiai, M., Matsumoto, Y., Sato, T., Ohnishi, M., Okabe, N., Kishimoto, Y., ... Kuroda, S. (2010). Psychiatric comorbidity among patients with gender identity disorder. Psychiatry and Clinical Neurosciences, 64. 514-519.

Joel, D., Tarrasch, R., Berman, Z., Mukamel, M., \& Ziv, E. (2013). Queering gender: Studying gender identity in 'normative' individuals. Psychology \& Sexuality, 5, 291-321.

Kersting, A., Reutemann, M., Gast, U., Ohrmann, P., Suslow, T., Michael, N., \& Arolt, V. (2003). Dissociative disorders and traumatic childhood experiences in transsexuals. Journal of Nervous and Mental Disease, 191, 182-189.

Kuyper, L., \& Wijsen, C. (2014). Gender identities and gender dysphoria in the Netherlands. Archives of Sexual Behavior, 43, 377-385.

Maccoby, E.E., \& Jacklin, C.N. (Eds) (1974). The psychology of sex differences (Vol.1). Palo Alto, CA: Stanford University Press.

McGlone, M.S., \& Aronson, J. (2006). Stereotype threat, identity salience, and spatial reasoning. Journal of Applied Developmental Psychology, 27, 486-493.

McNeil, J., Bailey, L., Ellis, S., Morton, J., \& Regan, M. (2012). Trans mental health study 2012. Retrieved from www.scottishtrans.org.

METRO Youth Chances. (2014). Youth Chances summary of first findings: The experiences of LGBTQ young people in England. London: METRO.

Moody, C., \& Smith, N.G. (2013). Suicide protective factors among trans adults. Archives of Sexual Behavior, 42, 739-752.

Monro, S. (2007). Transmuting gender binaries: The theoretical challenge. Sociological Research Online, 12. Retrieved from http://www.socresonline.org.uk/12/11/monro.html.

Monro, S. (2010). Towards a sociology of gender diversity. The Indian and UK cases. In S. Hines \& T. Sanger (Eds), Transgender identities. Towards a social analysis of gender diversity (pp. 242-258). New York: Routledge.

Nestle, J., Howell, C., \& Wilchins, R. (2002). Genderqueer: Voices from beyond the sexual binary. New York: Alyson Books.

Nieder, T.O. (2014). Praxisbuch Sexuelle Störungen: Sexuelle Gesundheit, Sexualmedizin, Psychotherapie sexueller Störungen Chapter: Entfernt, das andere Geschlecht, um genderqueerness :Eine theoretische und praktische Annäherung[ From being the other sex to genderqueerness: A theoretical and practical approximation]. In K. Schweizer, F. Brunner, S. Cerwenka, T. O. Nieder \& P. Briken (Eds.), 
Sex and Gender: Perspectives from psychosocial, cultural and sex sciences (pp. 167-179). Giessen: Psychosozial Verlag.

Nieder, T.O., \& Richter-Appelt, H. (2011). Tertium non datur Either/or reactions to transsexualism amongst health care professionals: The situation past and present, and its relevance to the future. Psychology \& Sexuality, 2, 224-243.

Rankin, S., \& Beemyn, G. (2012). Beyond a binary: The lives of gender-nonconforming youth. About Campus, 17, 2-10.

Richards, C., \& Barker, M. (2013). Sexuality and gender for mental health professionals: A practical guide. London: Sage.

Richards, C. \& Seal, L. (2014). Reproductive issues for trans people. Journal of Family Planning and Reproductive Health Care, 40(4), 245-247.

Roen, K. (2015). Intersex/DSD. In C. Richards \& M.J. Barker (Eds.). The Palgrave handbook of the psychology of sexuality and gender (pp. 183-197). London: Palgrave-Macmillan.

Rotondi, N.K., Bauer, G.R., Scanlon, K., Kaay, M., Travers, R., \& Travers, A. (2013). Nonprescribed hormone use and selfperformed surgeries: 'Do-it-yourself' transitions in transgender communities in Ontario, Canada. American Journal of Public Health, 10, 1830-1836.

Simon, L., Zsolt, U., Fogd, D., \& Czobor, P. (2011). Dysfunctional core beliefs, perceived parenting behavior and psychopathology in gender identity disorder: A comparison of male-to-female, female-to-male transsexual and nontranssexual control subjects. Journal of Behavior Therapy and Experimental Psychiatry 42, 38-45.
Sue, D.W. (2010). Microaggressions in everyday life: Race, gender and sexual orientation. Hoboken, NJ: Wiley.

T'Sjoen, G., Van Caenegem, E., Wierckx, K. (2013). Transgenderism and reproduction. Current Opinion in Endocrinology, Diabetes and Obesity, 20, 575-579.

United Nations (2011). Discriminatory laws and practices and acts of violence against individuals based on their sexual orientation and gender identity. Geneva: UN General Assembly Human Rights Council. Retrieved from: http:// www.ohchr.org/Documents/Issues/Discrimination/A.HRC. 19.41_English.pdf

Van Caenegem, E., Wierckx, K., Elaut, E., Buysse, A., Dewaele, A., Van Nieuwerburgh, F., ... T'Sjoen, G. (2015). Prevalence of gender nonconformity in Flanders, Belgium. Archives of Sexual Behavior, 44(5), 1281-1287.

WHO (World Health Organization). (1992). International Classification of Diseases 10 (2nd ed.). Geneva: World Health Organization.

World Professional Association for Transgender Health (WPATH). (2011). Standards of care for the health of transsexual, transgender and gender nonconforming people (7th ed.). Minneapolis, MN: WPATH.

Wylie, K., Barrett, J., Besser, M., Bouman, W.P., Bridgman, M., Clayton, A., ... Ward, D. (2014). Good practice guidelines for the assessment and treatment of adults with gender dysphoria. Sexual and Relationship Therapy, 29, 154-214. 